\title{
Native English-Speaking Teachers versus Non-Native English-Speaking Teachers
}

\author{
Iván García Merino \\ University of Northern Iowa
}

\begin{abstract}
There is a stereotype that takes for granted that a native speaker is by nature the best person to teach his/her foreign language. This assumption leaves little room for non-native teachers. A comparison of these two kinds of teachers is made following Medgyes' 3 dimensional framework: native/non-native, nonnative/non-native and native/native. The aim of this article is to analyze their differences in order to prove that non-native teachers have some advantages which should be taken into account.
\end{abstract}

A long time ago, when I was nineteen, I changed my major from Geography and History to English Language and Literature. From that day on, I knew that one day I would become an English teacher. But on that day also began the frustration of many non-native English-speaking teachers (non-NESTs): the stereotype that native English-speaking teachers (NESTs) are better English teachers that non-NESTs. The purpose of this article is to see what can be done to counter this stereotype. However, the problem is not so simple, because it does not only go in one direction. Native-speaking teachers (NSTs) are not always NSTs and non-NSTs are not always non-NSTs. The roles can switch, for example, when I was at the University of Northern Iowa (UNI) I applied for a Spanish teaching assistantship position in the Modern Language Department. I did not obtain it and that deeply hurt my pride as a native speaker. Later, I met three persons who received such assistantships; all were Americans. The first thought that came into my mind was that my proficiency in Spanish was, and always would be, much better than theirs; thus I should 
have obtained an assistantship before they did. Afterwards, on reflection, I was ashamed to realize that I was harboring the same prejudice that I wanted to counter! Smith pointed out that "Native speakers need as much help as non-native speakers when using English [or any other language] to interact internationally. There is no room for linguistic chauvinism" (7).

From my personal experience, it seems many people from England, Spain and France believe that they speak better than people from the USA, Hispanic America and Quebec, respectively. Amusingly, there are internal differences within these countries (e.g., in Valladolid the inhabitants boast that they speak the best Spanish of all). Kachru points out that English is now the language of those who use it. These users give it a distinct identity in every region. The aim of this article is to provide an answer to the following question: Are native speakers better English teachers than non-native speakers?

Taking into account that the stereotype "native speaker is better" is still active (as a questionnaire designed by myself at UNI showed), the advantages and disadvantages of NESTs versus non-NESTs are discussed following Medgyes' 3 dimensional framework:

\section{The native / non-native dimension}

What are the characteristics of non-NESTs? Medgyes points out that non-NESTs usually feel unsafe using the language they have to teach. Due to this fear, they tend to adopt two kinds of attitudes: pessimistic or aggressive. In my opinion, the latter is typical of the worst kind of teachers because, as Kachru and Nelson point out, non-NESTs have a linguistic insecurity that provokes a prescriptive and intolerant attitude. Fortunately for students, Medgyes believes that the pessimistic type is the most common one. This kind is obsessed with grammar and pays little attention to pronunciation and vocabulary, and almost none to linguistic appropriateness. They seem to have in mind Widdowson's belief that no one can learn a language without learning its grammar.

Medgyes states that by being both teacher and learner at the same time, non-NESTs are driven into a constant state of schizophrenia. He ironically points out that sooner or later non-NESTs tend to regret having chosen this career because there are not many options aside from having a nervous breakdown. One of the options is total resignation, and another is restricting the language to those rules which he or she has learn or mislearned. Medgyes argues that non-NESTs should openly acknowledge that they are students of English as well. This would be the best way to take a more confident stance in the classroom.

The aggressive type of teacher, on the other hand, operate on mistaken beliefs and prejudices about how language works. These false assumptions will turn into errors of all kinds: phonological, structural and semantic. Medgyes has observed that aggressive nonNESTs tend to be grammar-centered. They believe that knowing grammar means knowing a language. However, sometimes they are ignorant of a rule or mislearned it when they were students. Then they commit errors which are afterwards transmitted to their students. Medgyes states that they avoid using alternative sources to teach pronunciation such as radio, video, cassette recorder, etc. The reason is that they try to hide their deficiencies, 
such as their foreign accent, from their students. It is a way to save face in the classroom. Pronunciation is not their only Achilles' heel: non-NESTs' lexicon is another burden. The English language is estimated to have over 400,000 words. It is something that cannot be completely mastered (neither by native speakers nor by non-native speakers). However, native speakers have a Sprachgefiihl that can often help them to know if a word used by a student is right or not. The only way out for aggressive teachers is to play it safe: they use the words that are known to them. Many times these words have hidden connotations or are out-of-date or slang.

Another field where non-NESTs have deficiencies is in the cultural context. The choice of language has to match the social situation of the interaction and depends on the context. Medgyes points out that different cultures view the world in different ways. It is very complicated for a non-NEST to teach a topic that he or she may be ignorant about. Medgyes defines this phenomenon, the relation between the linguistic form and objects or events in the outside world, as referential appropriateness. It is very common for nonnative speakers to use structures that native speakers would not use in the same situations. This is a cultural aspect that cannot be separated from language and often leads to pragmatic failures.

In short, according to Medgyes, teachers that are either apathetic or aggressive feel guilty because they try to acquire a native command of English, and this goal is unreachable. Medgyes believes that the only possible cure is from the very beginning, for non-NESTs to make clear to their students that they are themselves simply more advanced learners of English. Medgyes' beliefs that a non-NEST will always be unable to acquire a native command of English can be better understood within Selinker's Interlanguage continuum. Medgyes points out that in 1972 Selinker designed a way to explain the development of $\mathrm{L} 2$ students. The latter described the learning process as an Interlanguage continuum:

\section{Interlanguage continuum}

UG 1---o.--l L2

Zero competence $(0 \%)=============================>$ Native (100\%)

Selinker stated that L2 learners are somewhere along the continuum, and that the learning process consists of going from one extreme to the other. Medgyes argues that this schema has to be represented in a more realistic way:

Interlanguage continuum

UG 1 -...--

Zero competence $(0 \%)====$ Near-native $(90-95 \%) \Rightarrow$ Native $(100 \%)$

Medgyes has brought up the controversy of whether a non-native speaker can ever become a native speaker or not. He believes that a non-native speaker's competence is limited, and that only a reduced group can reach near-native speaker's competence, "but sooner or later they are halted by a glass wall" (342). Medgyes admits that a few have managed to climb over it, such as Jozef Teodor Konrad Korzeniowski, alias Joseph Conrad. Medgyes 
justifies his stance by pointing out that non-native speakers are by nature norm-dependent. That is to say, their use of English is just an imitation formed from a native model. This is why non-native speakers are always better able to reach communicative goals in their L1. Coppieters seems to be more flexible. She points out that there are many people whose L2 has become their L1. With the exception of the accent, native speakers cannot distinguish them from themselves. She calculates that these speakers are at about $90 \%$ to 95\% in their acquisition along the interlanguage continuum.

Other authors completely disagree with his view. Greenbaum (in Kachru 1985) argues that, "There is no doubt that non-native speakers can acquire native-like proficiency in English as an additional language, whether they belong to the 'outer circle' (ESL) or the 'expanding circle' (EFL)" (31). Coppieters carried out an empirical study to see if there was a difference in competence between native and near-native speakers. Her study showed that there are differences in both groups' intuitions even when some of the nearnative speakers did not have a foreign accent. One of the reasons she gave is that adult learners cannot go through the same stages that children do when acquiring their L1. Coppieters observed that native and near-native speakers have the same proficiency and are equal in their level of language use. She discovered that native speakers and nearnative speakers develop a different grammar (or a different perception of grammar) and proposed that a language does not impose a specific underlying grammar on its speakers. Furthermore, although native speakers vary among themselves as well, near-native speakers lie outside the boundaries of native speakers' variation. Most of the variation between different speakers is in the functional and cognitive aspects of grammar. After all, a speaker of a given language is a speaker who is accepted by the speech community as such, not someone who is endowed with a specific underlying linguistic system. Lederer points out that even truly bilingual speakers are extremely rare. One of their languages becomes dominant and the speaker loses fluency in the other one.

The difference in the competence between native speakers and non-native speakers has been discussed above. Now the relation between language competence and teaching ability will be analyzed. Reves and Medgyes posit three hypotheses in relation to NESTs and nonNESTs: (1) "NESTs and non-NESTs differ in their teaching behavior" (354), (2) "These differences in teaching behavior are largely due to divergent levels of language proficiency" (354), and (3) "The awareness of differences in language proficiency influences the non-NESTs' self-perception and teaching attitudes" (354). Medgyes formulates two questions relating to these first two hypotheses: (a) "Is it true that, by virtue of having a better command of English, NESTs perform better in the classroom?" and conversely, (b) "Is it true that the more deficient the teacher is in English, the less efficient he or she is bound to be?" (346).

Medgyes admits that language competence is the point where non-NESTs are inevitably handicapped. The ways in which non-NESTs are deficient in the TL was previously discussed above. However, one cannot generalize that all non-NESTs are deficient users of English. They may have some gaps as NESTs have gaps in their L1. Medgyes points out that NESTs are only potentially superior and that in some cases nonnatives do better in certain areas of language use. Medgyes found that every non-NEST has his or her own problems when using English; however, he found some patterns in the 
areas of difficulties. The most frequent areas are: fluency and vocabulary, followed by speaking, pronunciation, and listening comprehension. At the bottom of the list were grammar, idiomatic expressions, appropriacy, intonation, and prepositions. In a study based on a survey with 216 EFL/ESL teachers, Reves and Medgyes found that most of the non-NESTs (74\%) considered their English to be 'good' or 'average'. Ten per cent considered their command to be 'excellent', and only one percent admitted having a 'poor' command. The authors state that the higher the grade of sophistication they achieve, the more self-critical and self-conscious non-NESTs become. These results show that about eighty-four per cent, more than four fifths, are not very highly sophisticated. Many of them may think that they know English, but they do not. Reves and Medgyes analyze the different areas of difficulty:

(1) Vocabulary: There are some problems with the English lexicon as well as with any other language: many words have different meanings according to the context, idioms, synonyms, etc. In short, vocabulary resists mastery.

(2) Fluency: Oral fluency requires many qualities, such as readiness to speak, speech rate, etc, in which non-NESTs are in a disadvantage. Non-NESTs' speech tends to be redundant and clumsy due to the difficulty in finding the right structures at the right time.

(3) Pronunciation: It is obvious that non-NESTs are marked by a foreign accent that in the worst cases interferes with other people's understanding.

(4) Grammar : Grammar is the favorite field for non-NESTs. It is said to be more concrete and more learnable than vocabulary. But who are more strict with errors made by their students? Janopoulos finds that faculty are more tolerant of non-native speakers' writing errors than of writing errors made by native speakers, suggesting that non-native students may not be held to the same standards as native speaker students. Janopoulos seems to include NESTs and non-NESTs under just one word faculty. According to the topic of this article, a distinction between NESTs and non-NESTs within the faculty staff is necessary. In my opinion, based on experiences with many language teachers and professors from four different universities in three different countries, non-NESTs are much more strict with grammatical and spelling errors made by their students (non-native speakers) than NESTs, who are more concerned with fluency and communication. This raises the following question: what would be the most likely reaction of a native speaker corrected by a non-native speaker? In my opinion based on my personal experience, native speakers become very ashamed and defensive if corrected by a non-native speaker. I believe that this is due to the misinterpretations of the concept native speaker discussed above.

Medgyes points out that if language competence were the only variable involved in the teaching skill, NESTs (with or without a teaching degree) would always be better than non-NESTs. As real life shows that this is not the case, this implies that there are additional variables to be considered in teaching. These are: experience, age, sex, aptitude, charisma, motivation, training, etc. Medgyes wonders whether, if all these variables were equal between a NEST and a non-NEST, the NEST would be superior due to his or her better language competence. He does not think so. He states that in his own experience, "native and non-natives stand an equal chance of achieving professional success" (346). The explanation is that it is precisely their deficient language competence that enables 
them to compete with native speakers, above all in monolingual EFL settings. Finally, it has to be taken into account that non-NESTs usually follow a standard variety, whereas NESTs often speak a non-standard variety.

Once it has been shown that language competence is not the overriding factor, the variable of teaching differences between NESTs and non-NESTs is taken into account. Reves and Medgyes found that two-thirds of their subjects saw differences in teaching behavior between NESTs and non-NESTs. Palfreyman points out that these two groups have different approaches to talking and thinking about language. He found that there is a different kind of language-related awareness. NESTs are more aware of the correct use, but non-NESTs are more aware of structural patterns and of language-learning processes. This makes the non-NESTs more rigid and more knowledgeable at the same time. Palfreyman conducted an empirical experiment with two NESTs and two non-NESTs designing a lesson plan. He discovered that there were two approaches in the way that the language system was represented: analytic and synthetic. The former corresponds to the two NESTs. They tried to establish distinctions, on the basis of context-free principles such as generalized semantic definitions and word-forms. It is the way native speakers bring order to their unconscious linguistic knowledge into the classroom.

The latter approach, the synthetic, was characteristic of the two non-NESTs. They aimed to integrate language into a situational or linguistic context. This developed from having to cope with English-speaking situations.

These two approaches influence the perception teachers have about their students' linguistic knowledge. The NESTs tend to see learning as a matter of making their students consciously aware. On the other hand, non-NESTs are concerned not with language, but with the ability to mean. Nonetheless, Reves and Medgyes seem to disagree by concluding that NESTs are more natural and real with language (that is to say, communication is more important than form), whereas non-NESTs are more concerned with accuracy and formal features of English. The latter try to isolate language from context, because they are afraid of losing control of the teaching material. Lederer points out that non-NESTs tend to consider morphological mistakes more serious, whereas NESTs place emphasis on pronunciation and syntax. The reason is that word order is a structural pattern that NESTs learn subconsciously; they take it for granted. However, even highly educated native speakers, who were not educated in linguistics, would not know how to explain word order in English. For instance, Lederer states that they know that the sentence: 'He came home drunk yesterday' is fine, and that the sentence: * 'He came drunk yesterday home' is not. Lederer states, "Our brain, because it is not programmed to accept this syntactic arrangement, sends back signals saying 'This sequence does not compute"' (3).

Reves and Medgyes found that a quarter of their respondents thought that NESTs were more successful teachers, conversely another quarter considered non-NESTs to be more successful. Half of the respondents did not see any difference.

The next question Reves and Medgyes refer to is whether non-NESTs' defective in English hampers their teaching. Less than a quarter answered that it did not. The majority said that it interferes 'a little' and 'quite a bit'. Only four per cent admitted that it interfered 'very much' or in an 'extreme' way. They showed that non-NESTs prepare their classes more carefully; this could be a strategy for solving their problem with 
language proficiency. On the other hand, NESTs tend to improvise more and not to follow the textbook as closely. They found that the better trained teachers were more selfconfident, assessed their students' learning capacities more accurately, were more generous with their value judgements, and were employed in the best schools. After this analysis, we still cannot answer the question about who is more successful. This question has no answer since it is based on subjective perceptions. This is probably why Reves and Medgyes found that the respondents' answer to that question was balanced.

Medgyes enumerates six points where a non-NESTs is better than a NEST:

(a) "Only non-NESTs can serve as imitable models of the successful learner of English" (346). Lederer points out that if all language teachers are native speakers the students would reach the conclusion that one has to be born in an English speaking country to learn to speak English. Medgyes points out that non-NESTs have been, and still are, learners of English. They are successful learners and they can become models for their students. The teachers use their learning experience in a reflective way in their teaching. Widdowson makes a distinction between the role of the instructor and the role of the informant. He considers that a native speaker may have the edge as an informant, i.e., he or she can be a perfect language model; but the instructor's role is a different matter. The NEST cannot be a learner model because he or she did not have to learn English as a second language.

(b) "Non-NESTs can teach learning strategies more effectively" (346). As the nonNEST is a teacher and a learner at the same time, he or she has developed learning strategies that can be useful to his or her students. On the other hand, NESTs may lack these strategies.

(c) "Non-NESTs can provide learners with more information about the English language" (347). Non-NESTs have learned about how the English language works during their own learning process. This makes them better informants than their native colleagues. Reves and Medgyes point out that NESTs may not be aware of the internal mechanisms operating in the acquisition of a second language, since for NESTs language acquisition was unconscious.

(d) "Non-NESTS are more able to anticipate language difficulties" (347). According to Larsen-Freeman and Long the Contrastive Analysis Hypothesis (CAH) said that by contrasting two languages, phonological, morphological/lexical, syntactic, and pragmatic errors can be predicted. Errors occur because where two languages are similar, positive transfer would occur, whereas where they were different, negative transfer, or interference, would result. However, when the predictions arising from the $\mathrm{CAH}$ were finally subjected to empirical tests, serious flaws were revealed. While CAH predicted some errors, it clearly did not anticipate all (i.e., it underpredicted). Furthermore, some errors it did predict failed to materialize (i.e., it overpredicted). In short, Larsen-Freeman and Long have estimated that between $23 \%$ and $51 \%$ of the errors occur due to the transfer from $L 1$. In my opinion, a non-NEST could, and should, take advantage of CAH in its partial validity.

(e) "Non-NESTs can be more empathetic to the needs and problems of their learners" (347). As non-NESTs are learners, they are still struggling with English and this makes them more sensitive and understanding with their students. 
(f) "Only non-NESTs can benefit from sharing the learner's mother tongue" (347). In a monolingual setting, for instance that of Spanish speakers teaching English in Spain, their mother tongue can be used as a vehicle of communication. It can help in the learning process in many ways. For example, if a student asks what 'moose' means, it would not be difficult for a NEST to explain the meaning in English. But there is the chance that the students may think of a 'deer', 'elk' or 'reindeer' instead. In this case, it would be easier to use the students' language to translate the term. But it can get even worse. If a beginner asks for the meaning of an abstract word such as 'remorse', it would be extremely difficult for a NEST to make the students understand. Much time can be saved by just translating the word into the students' L1. In the TESOL '96 Conference in Chicago, Fisk and Ong pointed out that ESL/EFL teachers have a bias against translation. They believe that it is based on abuse of translation by the grammar-translation method. Translation can be used as well as abused. Where it is a helpful strategy, why not to make use of it? They proposed to use translation in the most rational way: 'English mostly' versus 'English only'.

Medgyes concludes that these advantages tend to balance the non-NESTs' language competence deficiencies. Therefore, he states, "The more proficient in English, the more efficient in the classroom is a false statement" (347).

\section{The second dimension: non-native / non-native}

Medgyes compares non-NESTs among themselves. He agrees that if all the other variables are equal, the non-NEST with higher proficiency in English would be the better teacher. Therefore, he points out that the most important professional duty for non-NESTs is to improve their command of English as much as possible. There are two major problems that make this goal difficult to achieve: lack of time and fossilization. In my opinion, the best way to avoid fossilization and acquire a high proficiency in English is to live in the target language (TL) country for a long time. Reves and Medgyes found that ten per cent of the respondents said that they had stayed in English speaking countries for more than one year, whereas $86 \%$ had never been in an English speaking country. The rest stayed for periods of between one year and less than a month. They also found that non-NESTs considered that having high qualifications improves one's chances of spending time in an English speaking country. This probably entails making friends and therefore, having the chance to keep in touch with native speakers. This influences the motivation to work together with NESTs. But the most important factor is, as Spolsky points out, that frequent contact between non-NESTs and native speakers helps the former to improve their English even when the native speakers use foreigner talk. However, Reves and Medgyes add that that frequent contact can also have a negative effect. Non-NESTs can become aware of their deficiencies and become more critical and, as a consequence, lose their self-esteem.

\section{The third dimension: native / native}

Medgyes believes that the assertion: "The more proficient, the more efficient" (348) is absurd for this dimension. Although there are differences in performance among native 
speakers, there are no differences in L1 competence. In their case, NESTs have to try to minimize the deficiencies mentioned above. Medgyes believes that if a NEST is at the same time a learner of a foreign language, the drawbacks can be counterbalanced. This is particularly important in the monolingual setting. For instance, if a NEST is teaching in Spain, it would be most helpful for him or her to learn Spanish. Because of this fact, Medgyes modifies the original statement ('The more proficient, the more efficient') to "The more proficient in the learners' mother tongue, the more efficient in the classroom" (348). This is important in both ways. It not only helps in using the students' L1, but also it helps NESTs to improve their knowledge of grammar in their own language.

\section{Conclusion}

It has been shown through the questionnaire that the belief that NESTs are better English teachers than non-NESTs is still prevalent. Medgyes pointed out six non-NEST advantages that overcome the presumed superiority of the NESTs. In my opinion, it is as wrong to say that a NEST is always better than a non-NEST, as to state the contrary. I believe that it depends on the particular teaching situation. However, I share Medgyes' opinion that the ideal school is one which has a good balance of NESTs and non-NESTs. One group can complement the other in their strengths and weaknesses. Lederer pointed out that any kind of discrimination against non-NESTs should be avoided in foreign language departments. I would like to extend this idea further and include both groups. In my opinion, any discrimination against non-NESTs or NESTs should be avoided in education, from kindergarten to university. An example of discrimination against NESTs comes to my mind. In high schools in Spain, English-teaching positions are exclusively reserved for Spaniards. I think this is as wrong as the attitude of the private language schools that are only interested in attracting students by boasting that they have many NESTs on staff. In my opinion, it would be ideal to have at least one NEST available in every private and high school. I think that non-NESTs could take care of the low level students and children, and leave the high level students to their NEST colleagues. Lederer points out that many private language schools use the word native speaker as bait without paying attention to their teaching and academic qualifications. Unfortunately, in both schools, public and private, employers are more concerned about the English proficiency of the applicants than with their teaching ability. Therefore, the concept 'English teacher' should be changed in these cases to 'English instructor'. An example of discrimination against non-NESTs is the JET program (Japan Exchange and Teaching Program). The program is sponsored by three government ministries and the local governments of Japan. One of the positions offered is as ALT (Assistant Language Teacher). ALTs are assigned to public schools or boards of education. The pamphlet states: "Duties may include teaching with Japanese teachers of English, preparing supplementary teaching materials, coordinating English language clubs and other extracurricular activities, assisting with teacher-training, and engaging in local international exchange activities". The eligibility criteria, among others, are: (1) Be a U.S. citizen by the first week of December, 1996; and (2) Hold or obtain a bachelor's degree by June 30, 1997. The JET program is discriminating against non-NESTs by taking for granted that a native speaker without a teaching degree (just a bachelor's degree in any 
field) is better in an EFL setting than a non-native speaker of English with a teaching degree and maybe some knowledge of Japanese. This helps to spread the false assumption that anyone born in an English-speaking country can teach English. This can lead to unrealistic expectations for foreign language students. If a native speaker of English without teaching qualifications is teaching in Spain and a student asks him or her why a particular sentence is wrong, it is not enough to answer that it is wrong because it does not sound right or even worse, because he or she says so. I believe that a student needs an answer that can help him or her to produce grammatical sentences in the future and to know why some structures are wrong or right.

Ideal teachers could be divided into two groups: the ideal NEST and the ideal nonNEST. The ideal NEST would be the one who could minimize the six advantages of nonNESTs referred by Medgyes. It is especially important that the NEST learns a foreign language, in particular the students' L1. On the other hand, the ideal non-NESTs teacher is one who has achieved a near-native proficiency of English. As Medgyes points out, the higher the non-NESTs' proficiency level of English, the less self-conscious, hesitant and insecure they will be. However, I disagree with Medgyes on one point. He states, "... it would be an absurd idea to bring a characteristically English environment into another country" (5). A non-NEST who has lived for a long period of time in an English speaking country may have assimilated, to a certain extent, the TL culture. He or she would be in a suitable position to transmit to his or her students his or her perceptions about the TL culture (whether they are right or wrong). For example, it would be a good idea to use the American grading system to teach them how it works in the United States. Culture and language are so closely related that they cannot be separated one from another without destroying the whole. Lederer points out that the cultural aspects are extremely difficult if not impossible to acquire only through theoretical study without being directly exposed to it. On the other hand, I completely agree with Medgyes in that non-NESTs have to be made aware of their own advantageous potential as language teachers in comparison with NESTs, in order to help them assume a more favorable self-perception.

Widdowson also points out that TESOL has made public its opposition against any sort of discrimination against non-NESTs. The TESOL organization represents liberalism by rejecting any kind of discrimination against English teachers whether on the grounds of age, sex, religion, education, intelligence, or mother tongue.

To sum up, are native speakers better English teachers than non-native speakers? The answer has to be negative. No one is by definition better than the other. It depends on the teaching situation and the particular teacher; however, it is probably better to have a good balance of NESTs and non-NESTs in any institution.

\section{Works Cited}

Coppieters, Rene. "Competence Differences between Native and Near-native Speakers." Language 63.3 (1987): 544-73.

Edge, Julian. "Native, Speakers and Models." JALT Journal 9.2 (1988): 153-57.

Gass, Susan. "The Development of L2 Intuitions." TESOL Quarterly 17.2 (1983): 273-91. 
Janopoulos, Michael. "University Faculty Tolerance of NS and NNS Writing Errors: A Comparison." Journal of Second Language Writing 1.2 (1992): 109-21.

Kachru, B. Braj. The Other Tongue: English Across Cultures. Urbana, IL: University of Illinois Press, 1982.

Kachru, B. Braj. "Standards, Codification and Sociolinguistic Realism: The English Language in the Outer Circle." English in the World - Teaching and Learning the Language and Literatures. Eds. Quirk and Widdowson. Cambridge, UK: Cambridge University Press - The British Council, 1985. 11-30.

Kachru, B. Braj. The Alchemy of English. New York: Pergamon Press Ltd, 1986.

Kachru, B. Braj, and Nelson, L. Cecil. "World Englishes." Sociolinguistics and Language Teaching. Eds. McKay L. Sandra and Hornberger H. Nancy. Cambridge: Cambridge University Press, 1996. 71-102.

Larsen-Freeman, Diane, and Long, H. Michael. An Introduction to Second Language Acquisition. New York: Longman Inc, 1991.

Lederer, Herbert. "The 'Native Speaker' Issue: Problem or Pretext?" ADFL Bulletin 12.4 (1981): $1-4$.

Medgyes, Peter. "The Schizophrenic Teacher." ELT Journal 37.1 (1983): 2-6.

Medgyes, Peter. "Queries from a Communicative Teacher." ELT Journal 40.2 (1986): 107-12.

Medgyes, Peter. "Native or Non-native: Who's Worth More?" ELT Journal 46.4 (1992): 340-49.

Odlin, Terence. "The Introspective Hierarchy: A Comparison of Intuitions of Linguists, Teachers, and Learners." Perspectives on Pedagogical Grammar. Eds. Odlin, Terence. Cambridge: Cambridge University Press, 1994. 271-92.

Paikeday, M. Thomas. "May I Kill the Native Speaker?" TESOL Quarterly 19.2 (1985): 390-95. Paikeday, M. Thomas. The Native Speaker is Dead! Ontario, Canada: Paikeday publishing Inc, 1985.

Palfreyman, David. "How I Got it in my Head: Conceptual Models of Language and Learning in Native and Non-native Trainee EFL Teachers." Language Awareness 2.4 (1993): 209-23.

Reves, Thea., and Medgyes, Peter. "The Non-native English Speaking EFL/ESL Teacher's Selfimage: An International Survey." System 22.3 (1994): 353-67.

Selinker, Larry. "Interlanguage." IRAL 10 (1972): 219-31.

Smith, L. E. English as an International Language: No Room for Linguistic Chauvinism. Readings in English as a Second Language. Ed. Smith L. E. Oxford: Pergamon Press, 1983. 7-11.

Spencer, N. "Differences between Linguists and Non-linguists Intuitions of GrammaticalityAcceptability." Journal of Psycholinguistic Research 2 (1973): 83-98.

Spolsky, B. Conditions for Second Language Learning. Oxford: Oxford University Press, 1989.

Widdowson, H. George. "ELT and EL Teachers: Matters Arising." ELT Journal 46.4 (1992): 333-39.

Widdowson, H. George. "The Ownership of English." TESOL Quarterly 28.2 (1994): 377-89. 